\title{
Subclinical hypothyroidism (SCH) in first trimester of pregnancy.
}

1. MBBS, FCPS

Associate Professor Medicine Nishtar Medical University Multan.

2. MBBS, MCPS, FCPS

Assistant Professor Medicine

DG Khan Medical College Dera Ghazi Khan.

3. MBBS, FCPS

Consultant Physician

Teaching Hospital Dera Ghazi Khan.

4. MBBS

Final Year Student

Bakhtawar Amin Medical and Dental

College Multan.

Correspondence Address:

Dr. Kashif Ali Khan

Department of Medicine

DG Khan Medical College Dera Ghazi

Khan.

kashifnutkani@yahoo.com

Article received on:

20/01/2020

Accepted for publication:

05/03/2020
Muhammad Saleem Akhter ${ }^{1}$, Kashif Ali Khan², Kehkashan Fatima ${ }^{3}$, Muhammad Waqar Saleem ${ }^{4}$

ABSTRACT... Objectives: The prime objective of this study was to evaluate and asses the prevalence and related complications of $\mathrm{SCH}$ in pregnant ladies in their $1^{\text {st }}$ trimester of pregnancy in Pakistani population. Study Design: Cross Sectional study. Setting: Department of Medicine, Teaching Hospital, DG Khan, Pakistan. Period: $11^{\text {th }}$ February 2017 to $29^{\text {th }}$ December 2018. Material \& Methods: We obtained informed consent from all patients. 457 pregnant ladies having last missed period till $12^{\text {th }}$ week with age group between 18-45 years were included in this study. Samples were collected for T4 (Thyroxine), TSH (Thyroid Stimulating Hormone) and T3 (Triiodothyronine). Patients were followed for their entire pregnancy period. Adverse events and complications were noted. Results: Out of 457 patients who were included in our study, 169 subjects had TSH levels well above 4.6- $10 \mathrm{mIU} / \mathrm{L}$. 288 subjects were having TSH levels below $4 \mathrm{mIU} / \mathrm{L}$. The overall prevalence of subclinical hypothyroidism $(\mathrm{SCH})$ was found to be $37 \%$ in pregnant women during their first trimester of pregnancy. Pregnant women having subclinical hypothyroidism $(\mathrm{SCH})$ were having higher risks of loss of pregnancy, placental abruption and neonatal death rates as compared to euthyroid pregnant women. Conclusion: Our study concludes that overall prevalence of subclinical hypothyroidism $(\mathrm{SCH})$ in Pakistani pregnant women during their first trimester of pregnancy was found to be $37 \%$.

Key words: $\quad$ First Trimester, Pregnancy, Subclinical Hypothyroidism.

Article Citation: Akhter MS, Khan KA, Fatima K, Saleem MW. Subclinical hypothyroidism (SCH) in first trimester of pregnancy. Professional Med J 2020; 27(11):24742477. https://doi.org/10.29309/TPMJ/2020.27.11.4495

\section{INTRODUCTION}

Subclinical hypothyroidism $(\mathrm{SCH})$ is defined by increased thyrotropin levels (TSH) with normal tetra iodothyronine (T4) levels in serum. Recent guidelines define the upper limit of TSH in third trimester of pregnancy to be $4.6 \mathrm{mIU} / \mathrm{L} .{ }^{1-2}$ Pakistan is one of the developing countries with many families living below poverty line, suffering from many nutritional deficiency disorders including subclinical hypothyroidism ( $\mathrm{SCH}$ ). It has various negative outcomes on maternal and fetal health such as loss of pregnancy from miscarriage and intrauterine death. Other outcomes include premature labor, gestational hypertension, placenta previa and intrauterine growth restriction (IUGR). ${ }^{3}$

A systematic review on adverse effects of subclinical hypothyroidism ( $\mathrm{SCH}$ ) on fetomaternal health by Van Den Boogaard which included five articles only and tried to assess the impact of $\mathrm{SCH}$ with various negative outcomes in maternal and fetal health. It was concluded that it is one of the leading cause of loss of pregnancy, premature labor, gestational hypertension, placenta previa and intrauterine growth restriction. But its small sample size and minimum number of articles $(n=5)$ does not make pure sense to follow these findings and assume them in Pakistani population as well. ${ }^{4}$

During pregnancy, most of the fetal hormones in the first trimester of pregnancy are synthesized by maternal thyroid glands which diffuse to the fetus through placenta and perform various neurophysiological functions in fetus causing growth, development of CNS, CVS, musculoskeletal system and various other physiological functions. As during $1^{\text {st }}$ trimester of pregnancy, fetus is totally dependent on maternal 
thyroid hormones so subclinical hypothyroidism $(\mathrm{SCH})$ at this crucial stage of development may cause multiple fetal health related problems such as premature labor, gestational hypertension, placenta previa and intrauterine growth restriction (IUGR). ${ }^{5-6}$

The study was conducted to evaluate the possible prevalence of subclinical hypothyroidism $(\mathrm{SCH})$ in Pakistani female pregnant population. This study also highlights the complications associated with $\mathrm{SCH}$ in pregnant population in their $1^{\text {st }}$ trimester of pregnancy. Currently, there is no existing literature indicating possible prevalence of subclinical hypothyroidism (SCH) in Pakistani female pregnant population.

\section{MATERIAL \& METHODS}

This study was carried out at Department of Internal Medicine, Teaching Hospital, DG Khan, Pakistan. We explained the whole process of our study for the clarification of patient's concepts about our study. Informed consent was obtained from patients who were willing to be involved in research. It was cross-sectional study. This study was carried out from $11^{\text {th }}$ Feb 2017 to $29^{\text {th }}$ Dec 2018. After detailed history and examination, 457 pregnant ladies having last missed period till $12^{\text {th }}$ week with age group between $18-45$ years were included in this study. Blood samples were collected for thyroid functions tests (TFTs) for estimation of serum free T3, T4 and serum TSH. Patients were followed for their entire pregnancy period. Adverse events and complications were noted. SPSS windows version 22 was used to analyze the data. P-value of less than 0.05 was considered statically significant.We used student t-test to relate arithmetic means and parameters and Chi square test for categorical variables and Odds Ratio were calculated for different adverse events and complications.

\section{RESULTS}

Total 457 patients were included in our study. As for the occupation, 313 patients were housewives, 108 were laborers and 36 were the office working ladies. 319 subjects were uneducated, 118 studied till matriculation level while only 20 subjects studied till graduation or above. Mean age was $27 \pm 4.6$ years.

Out of 457 patients who were included in our study, 169 subjects had TSH levels well above 4.6$10 \mathrm{mIU} / \mathrm{L}$. The overall prevalence of subclinical hypothyroidism (SCH) was found to be $37 \%$ in pregnant women during their first trimester of pregnancy. In comparison to euthyroid pregnant ladies, pregnant women having subclinical hypothyroidism ( $\mathrm{SCH}$ ) were having higher risks of loss of pregnancy [R.R 2.03 Confidence Interval (CI) 1.67-2.47\}; $\mathrm{I}^{2}=0$ ], placental abruption [R.R 2.43\{Confidence Interval (Cl) 1.66-2.48\}; $\mathrm{I}^{2}=0$ ], and death of neonates [R.R 2.57\{Confidence Interval (CI) 1.47-4.37\}; $\mathrm{I}^{2}=0$ ]. We did not found any association between $\mathrm{SCH}$ and gestational hypertension, preterm labor, premature delivery or miscarriage, placenta previa and intrauterine growth restriction (IUGR).

\begin{tabular}{|l|c|c|}
\hline \multicolumn{1}{|c|}{ Various Outcomes of Pregnancy } & Relative Risk [Cl 95\% ] & (\%) \\
\hline Pregnancy loss & $2.03[1.67-2.47]$ & 0 \\
\hline Preterm labor & $0.94[0.57-1.53]$ & 39 \\
\hline Preterm delivery & $1.30[0.91-1.34]$ & 52 \\
\hline Gestational hypertension & $1.13[0.74-1.12]$ & 0 \\
\hline Placental abruption & $2.43[1.57-2.37]$ & 0 \\
\hline Placenta previa & $0.68[0.18-3.19]$ & 47 \\
\hline IUGR & $1.60[0.73-2.90]$ & 0 \\
\hline Neonatal death & $2.58[1.41-4.73]$ & \\
\hline
\end{tabular}

Table-I. Relative Risk ratios with confidence interval of $95 \%$ showing comparison of pregnant women in first trimester to euthyroid pregnant women for various pregnancy outcomes.

$\mathrm{R} . \mathrm{R}=$ relative risk; $\mathrm{Cl}$, confidence interval; IUGR= Intrauterine growth restriction. 


\section{DISCUSSION}

Pakistan is one of the developing countries with many families living below poverty line, suffering from many nutritional deficiency disorders including subclinical hypothyroidism ( $\mathrm{SCH}$ ) which may be caused by iodine deficient meals or lack of iodine supplementation in the form of iodized salt. $250 \mu \mathrm{g}$ intake of iodine is highly recommended during entire pregnancy period daily. ${ }^{7-8}$ Owing to enhanced placental uptake, hemodilution, elevated thyroid binding globulins (TBG) and urinary loss during pregnancy cause 30-35\% increased requirement for T3 and T4.As we know that during $1^{\text {st }}$ trimester of pregnancy, fetus is totally dependent on maternal thyroid hormones as most of the fetal hormones during first trimester of pregnancy are synthesized by maternal thyroid glands which diffuse to the fetus through placenta and perform various neurophysiological functions in fetus causing growth, development of CNS, CVS, musculoskeletal system and various other physiological functions. During pregnancy, iodine deficiency may be caused by iodine deficient meals or lack of iodine supplementation in the form of iodized salt, hemodilution, urinary loss of iodine making feto-placental unit an iodine deficient unit. ${ }^{9-12}$

The number and severity of complications depend upon severity of hypothyroidism in pregnancy as well as trimester of pregnancy as feto-placental unit needs more iodine during $1^{\text {st }}$ trimester of pregnancy which performs various neurophysiological functions in fetus causing growth, development of CNS, CVS, musculoskeletal system and various other physiological functions. The severity of complications defines type and urgency of treatment as well. The early diagnosis followed by appropriate treatment decreases the frequency of various adverse outcomes such as loss of pregnancy from miscarriage and intrauterine death, premature labor, gestational hypertension, placenta previa and intrauterine growth restriction (IUGR). ${ }^{13}$

Pregnant women with previous history of miscarriages should be treated immediately and appropriately if the TSH antibodies or when TSH is around or above upper limit of normal. As there is $30-35 \%$ increased need for thyroid hormones, patients with $\mathrm{SCH}$ cannot meet with fetal requirements of thyroid hormones and multiple various complications arise. A study conducted by Negro et al showed the increased incidence of miscarriage by $15 \%$ for every $1 \mathrm{mlU} / \mathrm{L}$ rise in serum TSH levels. ${ }^{14}$

Our data concludes an overall prevalence of subclinical hypothyroidism ( $\mathrm{SCH}$ ) to be $37 \%$ in pregnant women during their first trimester of pregnancy. In comparison to euthyroid pregnant ladies, pregnant women having subclinical hypothyroidism $(\mathrm{SCH})$ were having higher risks of loss of pregnancy, placental abruption, death of neonate. While, we did not found any association between $\mathrm{SCH}$ gestational hypertension, preterm labor, premature delivery or miscarriage, placenta previa and intrauterine growth restriction (IUGR) and these findings also support the meta-analysis conducted by Spyridoula M. et al were found to be having similar findings that are found out in our study. ${ }^{15}$

\section{CONCLUSION}

Our study concludes that overall prevalence of subclinical hypothyroidism ( $\mathrm{SCH})$ in Pakistani pregnant women during their first trimester of pregnancy was found to be $37 \%$. Pregnant women having subclinical hypothyroidism $(\mathrm{SCH})$ were having higher risks of loss of pregnancy, placental abruption and neonatal death rates as compared to euthyroid pregnant women. In the light of these findings we recommend routine screening for $\mathrm{TSH}$, free T3 and free T4 during pregnancy especially during $1^{\text {st }}$ trimester of pregnancy.

Copyright $(05$ Mar, 2020.

\section{REFERENCES}

1. Upadhyaya TL, KC A, Paudel S. Prevalence and complications of Hypothyroidism during pregnancy in western Nepal. Nepal Journal of Medical sciences $2014 ; 3(1): 48-50$.

2. Glinoer D. Thyroid disease during pregnancy in Werner and Ingbar's.9th ed. philadelphia: lippincot Williams and Wilkins:2004. 
3 Maraka S, O'Keeffe DT, Montori VM. Subclinical hypothyroidism during pregnancy-should you expect this when you are expecting?: A teachable moment. JAMA Internal Medicine. 2015 Jul $1 ; 175(7): 1088-9$.

4. Wang S, Teng WP, Li JX, Wang WW, Shan ZY. Effects of maternal subclinical hypothyroidism on obstetrical outcomes during early pregnancy. Journal of Endocrinological Investigation. 2012 Mar 1;35(3):322-5.

5. Feldthusen AD, Larsen J, Pedersen PL, Kristensen TT, Kvetny J. Pregnancy-induced alterations in mitochondrial function in euthyroid pregnant women and pregnant women with subclinical hypothyroidism; relation to adverse outcome. Journal of Clinical \& Translational Endocrinology. 2014 Mar 1;1(1):e13-7.

6. Zoeller RT, Rovert J. Timing of thyroid hormone action in the developing brain: clinical observations and experimental findings. J Neuroendocrinol 2004; 16:809-16 http://dx.doi.org/10.1111/j.13652826.2004.01243.x.

7. Stagnaro-Green A, Chen X, Bodgen JD et al. Thyroid and pregnancy: a novel risk factor for very preterm delivery. Thyroid 2005; 15:351-57 http://dx.doi. org/10.1089/thy.2005.15.351.

8. Casey BM, Dashe JS, Wells CE et al. Subclinical Hypothyroidism and clinical outcome. Obstret Gynecol 2005; 105:239-45.
9. Nicholson WK, Robinson KA, Smallridge $\mathrm{RC}$ et al. Prevalence of postpartum thyroid dysfunction: $A$ quantitave review. Thyroid 2006; 16:573-82 http:// dx.doi.org/10.1089/thy.2006.16.573.

10. Sahu MT, DasV, Mittal S et al. Overt and subclinical thyroid dysfunction among Indian pregnant women and its effect in maternal and fetal outcome. Arch Gynacol Obstet 2010; 281:215-20 http://dx.doi. org/10.1007/s00404-009-1105-1.

11. Allan WC, Haddow JE, Palomaki GE, Williams JR, Mitchell ML, Hermos RJ, Faix JD, Klein RZ. Maternal thyroid deficiency and pregnancy complications: implications for population screening. Journal of medical screening. 2000 Sep 1;7(3):127-30.

12. Banerjee S. Thyroid disorders in pregnancy. J Assoc Physicians of India 2011; 59suppl:32-4.

13. Chen LM, Du WJ, Dai J, Zhang Q, Si GX, Yang $H$, Ye EL, Chen QS, Yu LC, Zhang C, Lu XM. Effects of subclinical hypothyroidism on maternal and perinatal outcomes during pregnancy: a single-center cohort study of a Chinese population. PloS one. 2014 Oct 29;9(10):e109364.

14. Stagnaro-Green A, Chen X, Bogden JD, Davies TF, Scholl TO. The thyroid and pregnancy: a novel risk factor for very preterm delivery. Thyroid. $2005 \mathrm{Apr}$ $1 ; 15(4): 351-7$.

15. Negro R, Schwartz A, Gismondi R et al. Increased pregnancy loss rate in thyroid antibody negative women with TSH levels between 2.5 and 5 in the first trimester of pregnancy. J clin Endocrino IMetab 2010; 95:E44-48 http://dx.doi.org/10.1210/jc.2010-0340.

\begin{tabular}{|c|c|c|c|}
\hline \multicolumn{4}{|c|}{ AUTHORSHIP AND CONTRIBUTION DECLARATION } \\
\hline Sr. \# & Author(s) Full Name & Contribution to the paper & Author(s) Signature \\
\hline 1 & M. Saleem Akhter & Main author & Chine \\
\hline 2 & Kashif Ali Khan & Co-author & resly \\
\hline 3 & Kehkashan Fatima & Review of literature. & \\
\hline 4 & M. Waqar Saleem & Manuscript writing, Editing. & \\
\hline
\end{tabular}

